2. Zahn FW. Untersuchungen über Thrombose. Virchowas Arch Pathol Anat. 1899;115:71.

3. Mas JL, Arquizan C, Lamy C, Zuber M, Cabanes L, Derumeaux G, et al. Recurrent cerebrovascular events associated with patent foramen ovale, atrial septal aneurysm, or both. $N$ Engl J Med. 2001;345:1740-6.
4. Loscalzo J. Paradoxical embolism: clinical presentation, diagnostic strategies, and therapeutic options. Am Heart J. 1987;114:141-5.

5. Mas JL. Diagnosis and management of paradoxical embolism and patent foramen ovale. Curr Opin Cardiol. 1996;11:519-24.

\title{
Ventricular assist device abdominal driveline infection: Treatment with platelet-rich plasma
}

\author{
Federica Jiritano, MD, Giuseppe Filiberto Serraino, MD, Lucia Cristodoro, MD, and \\ Attilio Renzulli, MD, PhD, Catanzaro, Italy
}

The contemporary trend toward left ventricular assist device (LVAD) implantation as a definitive treatment for end-stage heart failure has yielded a valid alternative for those patients who are not suitable candidates for heart transplantation and whose conditions are refractory to medical treatment. ${ }^{1}$ The long-term use of such devices, however, has brought into the spotlight a number of complications related to the interaction between the human body and the mechanical component. One of these is driveline infection, which in the worst-case scenario could lead to sepsis, forced explantation of the LVAD, or even death. ${ }^{2}$ The treatment is challenging and sometimes delayed because the problem occurs in patients already out in in the community. Vacuum-assisted closure (VAC) therapy, targeted antimicrobial therapy, and other advanced dressings have been proposed as valid treatments for driveline infections. ${ }^{3}$ We report 2 cases in which the previously mentioned measures failed to cure the infection, whereas continued topical application of autologous platelet-rich plasma (PRP) over the wound for about 2 weeks resolved the infection and closed the exit wound.

\section{CLINICAL SUMMARIES}

\section{Patient 1}

A 49-year-old man with end-stage cardiac failure (New York Heart Association functional class IV) was admitted with ascites and orthopnea. Five days after the hospital admission, the patient had acute abdominal pain, proctorrhagia, and anemia, necessitating urgent laparotomy.

\footnotetext{
From the Cardiac Surgery Unit, Magna Græcia University of Catanzaro, Catanzaro, Italy.

Disclosures: Authors have nothing to disclose with regard to commercial support. Received for publication Jan 24, 2013; revisions received Feb 9, 2013; accepted for publication Feb 28, 2013; available ahead of print March 25, 2013.

Address for reprints: Federica Jiritano, MD, Cardiac Surgery Unit, Magna Græcia University of Catanzaro, Catanzaro 88100, Italy (E-mail: fede.j@hotmail.it). J Thorac Cardiovasc Surg 2013;145:e69-70 $0022-5223 / \$ 36.00$

Copyright (c) 2013 by The American Association for Thoracic Surgery http://dx.doi.org/10.1016/j.jtcvs.2013.02.072
}

Ischemic colitis involving the rectum was found; it was resected, and a left colostomy was performed. Hemodynamic conditions improved steadily, and the patient was extubated on the third postoperative day. However he developed renal failure requiring hemodialysis. After 10 days, the HeartWare VAD system (HeartWare International, Inc, Framingham, Mass) was implanted. Seven days later, the skin around the exit site of the abdominal cable became erythematous with serum and purulent discharge. Escherichia coli was isolated, and intravenous treatment with ciprofloxacin was started on the basis of the antibiogram. After 1 week of antibiotic therapy, the infection had not improved. The exit site wound was then dressed every 3 days for a total of 5 times with autologous PRP until the 28th postoperative day, when it appeared completely closed with good tissue healing. Chronic kidney failure necessitating daily dialysis persisted. On the 32 nd postoperative day, the patient had acute cardiovascular and respiratory failure develop, necessitating mechanical ventilation and maximum inotropic support. Cardiac tamponade was diagnosed, and $1.5 \mathrm{~L}$ of bloodstained fluid was drained. The patient's cardiac function recovered, but he could not be weaned from mechanical ventilation and dialysis. He died on the 50th postoperative day of multiple organ failure. No signs of skin infection were found around the driveline.

\section{Patient 2}

A 50-year-old man who was obese (body mass index 36 $\mathrm{kg} / \mathrm{m}^{2}$ ) and had diabetes and dilated cardiomyopathy was admitted to hospital for end-stage cardiac failure. The patient underwent LVAD (HeartWare) implantation through a median sternotomy. His postoperative course was uneventful, and he was discharged on the 15 th postoperative day. On the 30th postoperative day, a purulent and smelly discharge developed at the abdominal cable exit site. Swabs were sent for culture, and multiresistant Acinetobacter baumannii (sensitive to colistimethate sodium [INN colistin]) and Staphylococcus aureus (sensitive to linezolid) were isolated. Intravenous antibiotic treatment targeted 

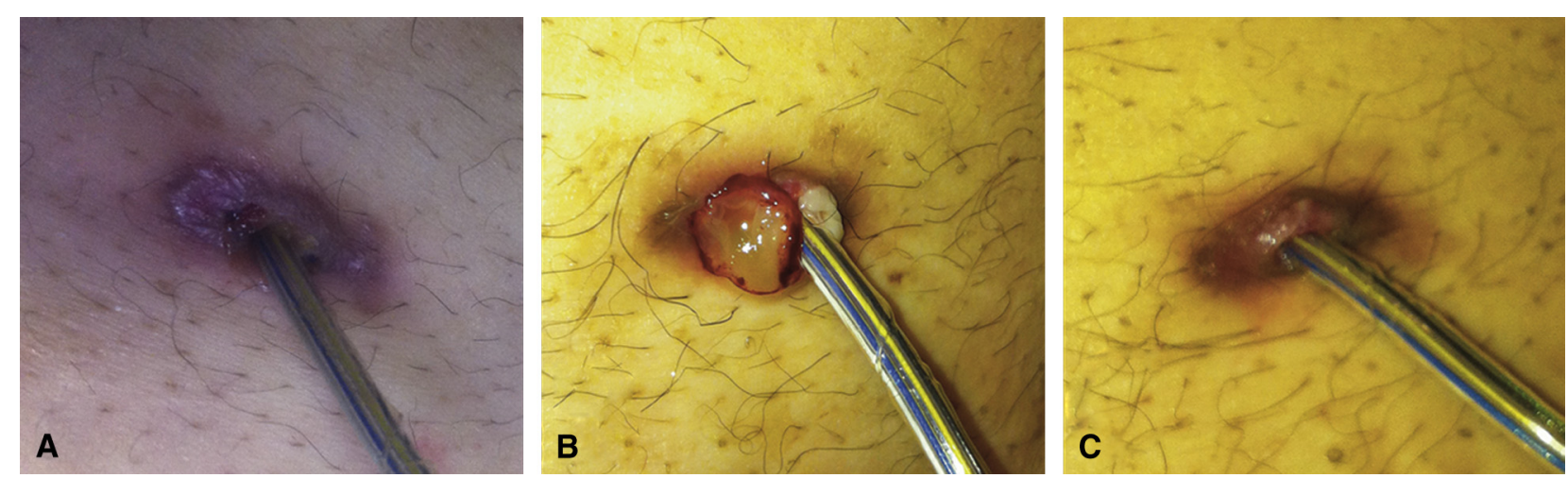

FIGURE 1. Photographs of patient 2. A, Infection of the abdominal driveline exit site despite antibiotic and vacuum-assisted closure therapy. B, Autologous platelet-rich plasma application over the infected wound. C, At 4-week follow-up after placement of the platelet-rich plasma dressing, good wound healing can be seen.

according to the antibiogram was started, together with local wound dressing with chlorhexidine gluconate. After 2 weeks of antibiotic treatment, the infection appeared worse, and VAC therapy was started. After a week of combined treatment, we did not observe any favorable response. VAC therapy was switched to local application of autologous PRP. The application and wound dressing were repeated every 3 days for 2 weeks, with the patient remaining in the community. After the treatment, the infection disappeared with good healing of the wound (Figure 1).

\section{DISCUSSION}

Driveline infection is a life-threatening LVAD complication that can lead to device removal, and it remains the foremost cause of death among patients with long-term mechanical assistance. ${ }^{2}$ Several therapeutic approaches have been proposed through the years to treat LVAD driveline infections, with controversial results. ${ }^{3,4}$ Some authors have proposed intravenous antibiotic therapy against germs, driveline immobilization, and aggressive surgical excision of the involved exit site. ${ }^{5}$ Despite aggressive therapy, however, cases of antibiotic refractory driveline infections are still reported.

In the early 1990s, PRP was proposed in the treatment of postsurgical infections, with good clinical results. ${ }^{6}$ During the inflammatory phase of tissue healing, activated platelets release specific growth factors. These include plateletderived growth factor, transforming growth factor- $\beta$, vascular endothelial growth factor, and epithelial growth factor. Platelet growth factor-together with other growth factors and cytokines-helps to regulate the early migration of cells to the injury site, cell mitosis, angiogenesis, granulation tissue formation, and bone regeneration. ${ }^{6}$ Furthermore,
Bielecki and colleagues ${ }^{7}$ showed that PRP inhibits the growth of $S$ aureus and $E$ coli in vitro. ${ }^{7}$ The antimicrobial action of white blood cells and platelets, both found in PRP, could reduce the development of driveline infection.

\section{CONCLUSIONS}

In our 2 cases, the topical application of autologous PRP helped in the treatment of abdominal driveline infection refractory to antibiotic treatment alone. The clinical cases here reported are the only cases with abdominal driveline infection observed in our institution. This is the first report to our knowledge of PRP use in the successful treatment of abdominal driveline infection refractory to antibiotic treatment alone.

\section{References}

1. Kirklin JK, Naftel DC, Pagani FD, Kormos RL, Stevenson L, Miller M, et al. Long-term mechanical circulatory support (destination therapy): On track to compete with heart transplantation? J Thorac Cardiovasc Surg. 2012;144: 584-603.

2. Zierer A, Melby SJ, Voeller RK, Guthrie TJ, Ewald GA, Shelton K, et al. Late-onset driveline infections: the Achilles' heel of prolonged left ventricular assist device support. Ann Thorac Surg. 2007;84:515-20.

3. Yuh DD, Albaugh M, Ullrich S, Conte JV. Treatment of ventricular assist device driveline infection with vacuum-assisted closure system. Ann Thorac Surg. 2005; 80:1493-5.

4. Schulman AR, Martens TP, Christos PJ, Russo MJ, Comas GM, Cheema FH, et al. Comparisons of infection complications between continuous flow and pulsatile flow left ventricular assist devices. J Thorac Cardiovasc Surg. 2007; 133:841-2.

5. Pasque MK, Hanselman T, Shelton K, Kehoe-Huck BA, Hedges R, Cassivi SD, et al. Surgical management of Novacor drive-line exit site infections. Ann Thorac Surg. 2002;74:1267-8.

6. Jameson CA. Autologous platelet concentrate for the production of platelet gel. Lab Med. 2007;38:39-42.

7. Bielecki TM, Gazdzik TS, Arendt J, Szczepanski T, Król W, Wielkoszynski T. Antibacterial effect of autologous platelet gel enriched with growth factors and other active substances-an in vitro study. J Bone Joint Surg Br. 2007; 7: 417-20. 